\title{
Cellular Analysis of Cutaneous Leishmaniasis Lymphadenopathy: Insights into the Early Phases of Human Disease
}

\author{
Glória Bomfim, Bruno B. Andrade, Silvane Santos, Jorge Clarêncio, Manoel Barral-Netto, and Aldina Barral* \\ Universidade Federal da Bahia, Salvador-Bahia, Brazil; Centro de Pesquisas Gonçalo Moniz, Fundação Oswaldo Cruz (FIOCRUZ), \\ Salvador-Bahia, Brazil; Instituto de Investigação em Imunologia, Instituto do Milênio, Salvador, Bahia, Brazil
}

\begin{abstract}
Lymphadenopathy is an early clinical sign in cutaneous leishmaniasis (CL), caused by Viannia parasites, and may help to understand the initial host response to these species of Leishmania. We report on characteristics of cells obtained from lymph nodes from cutaneous leishmaniasis patients with lymphadenopathy without ulceration (early phase, $N=21$ ) or lymphadenopathy and ulceration (late phase, $N=29$ ). Early-phase patients exhibited a higher proportion of neutrophils, eosinophils, and CD8+ T cells. Conversely, CD19+ B lymphocytes and plasma cells were more frequently observed in late-phase patients. The signal for IL-10 was significantly higher in late-phase patients; signals for IFN- $\gamma$ or IL-4 were similar in both groups. These data reinforce observations of an initial mixed Th1-Th2 profile as well as the early role of the CD8 T cell in cutaneous leishmaniasis. Additionally, there is a chronologic relationship between ulcer development and B-cell increase. IL-10 also increases at a late stage and may be important in limiting tissue damage.
\end{abstract}

\section{INTRODUCTION}

Cutaneous leishmaniasis (CL) is a vector-borne disease that represents a large burden to public health systems in developing countries. In endemic areas, widely distributed in tropical zones, early diagnosis is essential to reduce the harm the disease can do. We have previously demonstrated that efficient parasitological diagnosis can be made by needle aspiration of the lymph node (LN) from individuals suspected to be infected with Leishmania (L.) braziliensis, even before ulcers have been documented., ${ }^{1,2}$

Lymphadenopathy is observed in the early phases of human CL. ${ }^{1-3}$ Enlarged satellite LNs in patients who already display a cutaneous ulcer have been reported in both the Old and New Worlds. ${ }^{4-6}$ A bubonic form of leishmaniasis, with persistently enlarged LNs, has also been described. ${ }^{7}$ Moreover, a transitory lymphadenopathy can sometimes be the sole manifestation of L. braziliensis infection. ${ }^{2}$ LNs are described as important for parasite containment because the removal of regional LNs leads to faster and more disseminated disease in mice. ${ }^{8}$ These lymphoid tissues are also an early site of immune reaction, ${ }^{9}$ with cytokine production that may influence the outcome of the infection.

Experimental models of leishmaniasis have been successful in demonstrating that susceptibility and resistance are determined by the differential expression of Th1 or Th2 cell types. ${ }^{10}$ Leishmania survival depends on the balance of activating or deactivating cytokines acting on lymphocytes and macrophages. ${ }^{11}$ As major sites of immune response and lymphocyte trafficking, $\mathrm{LN}$ cell composition may reflect the balance of the different cell populations acting in the initial stages of CL. Moreover, in humans, differences in clinical presentation have also been described in patients with and without lymphadenopathy. ${ }^{3} \mathrm{CL}$ patients with lymphadenopathy display higher antibody titers and larger delayed-type hypersensitivity (DTH) reactions than those who have had the disease for a similar length of time but without LN enlargement. ${ }^{1,2}$ Little is known, however, of the LN cell composition in human CL at different phases of the disease. To better

* Address correspondence to Aldina Barral, Rua Waldemar Falcão, 121, Brotas, Salvador. E-mail: abarral@bahia.fiocruz.br characterize the cells-morphologically and phenotypicallyfrom the $\mathrm{LN}$ in the course of human CL, we performed fine needle aspiration of enlarged LNs in patients with CL infected by L. braziliensis at varying stages of the disease and immunologic alterations were compared.

\section{METHODS}

We performed fine needle aspiration of enlarged LNs from 51 patients with clinical aspects of CL from an endemic area of Bahia, Brazil (general demographic data: 38 male; age range 9-62 years old, mean 24.8 years). All patients had test results that were positive for lymphadenopathy in a parasitological test carried out by microscopic examination of LN smear and primary isolation by in vitro culture of aspirated material as previously described. ${ }^{2}$ Serodeme analysis was performed by an indirect immunofluorescence assay using a panel of anti-Leishmania monoclonal antibodies specific for members of the L. braziliensis, L. mexicana, and L. donovani species already described. ${ }^{12-14}$ Patients were evaluated and clinical examinations were performed focusing on clinical characteristics of the enlarged LN; detection of skin ulcers, duration of disease, and response to therapy were also noted. In addition to the parasitological diagnosis, the enrollment criteria were: presence of a palpable LN; fewer than 6 skin lesions (in those presenting skin ulcers on initial physical examination); absence of mucosal or visceral involvement; and absence of bacterial infection at the LN confirmed by culture. Informed consent was obtained from all patients enrolled, and this study was approved by Research Ethics Committee of the Hospital Universitário Professor Edgard Santos (Universidade Federal da Bahia).

Approximately $200 \mu \mathrm{L}$ of aspirated material was aseptically obtained. The total number of cells obtained through fine needle aspiration varied, ranging from $1.8 \times 10^{6}$ to $1.9 \times 10^{7}$ cells. From each volunteer, $1 \times 10^{6}$ cells were resuspended in $1 \mathrm{~mL}$ of RPMI 1640 (Gibco, Grand Island, NY) containing $5 \%$ of heat-inactivated calf fetal serum; $100 \mu \mathrm{L}$ of cells suspension was centrifuged at $800 \mathrm{rpm}$ for 10 minutes (Cytospin 2, Shandon Inc., Pittsburgh, PA) and stained with Diff-Quick stain set (American Scientific Products, McGraw Park, IL) for microscopic examination by two observers. Differential 
counting was performed for each 100 cells by optical microscopy $(\times 1000)$. Qualitative alterations were registered and reported.

A total $10^{6}$ cells/ mL obtained from LN aspiration of each volunteer were incubated with a panel of fluoresceinated monoclonal antibodies (Pharmingen, CA) for 30 minutes at $4^{\circ} \mathrm{C}$ as follows: anti-CD3 (30104X), anti-CD4 (30154X), antiCD8 (30325X), anti-CD19 (30664X), anti-CD56 (31665X), and anti-CD1 $\alpha$ (30169X). Control cells for cytometric analysis were incubated with isotype antibodies (fluoresceinconjugated IgG1, IgG2a, and IgG2b-Pharmingen, CA). Unlabelled cells were also used as cytometric analysis control in some assays. Afterward antibody incubation-labeled cells were washed 3 times in phosphate buffer saline and then analyzed by flow cytometry and CellQuest software v3.3 (Becton Dickinson, CA). At least 20,000 events were analyzed per sample.

Total RNA was isolated from LN cells without in vitro antigen stimulation using the RNAzolB (Tel-Test, Friendswood, TX). Briefly, phorbol myristate acetate (PMA)stimulated cell pellets from the LN aspirates or control samples (peripheral blood mononuclear cells) from normal individuals were resuspended in RNAzol B. After the addition of chloroform, the samples were centrifuged and the aqueous phase, containing the RNA, was collected. The RNA present in the aqueous phase was precipitated with isopropanol and washed twice with ethanol and then resuspended in diethylpyrocarbonate-treated water. All samples were frozen at $-90^{\circ} \mathrm{C}$ until validation tests. The RNA concentration was determined spectrophotometrically and its integrity evaluated through electrophoresis in $2 \%$ agarose gel as previously described. One microgram of total RNA was reverse transcribed by standard protocols. ${ }^{15}$ Aliquots of $2 \mu \mathrm{g}$ of each sample were submitted to reverse transcription (Superscriptase II, BRL Life Technologies, Grand Island, NJ) and primed with oligo(dT) ${ }^{12-18}$ (Pharmacia, Piscataway, NY) as described. After termination of the reaction by incubating at $90^{\circ} \mathrm{C}$ for 5 minutes, $2 \mathrm{U}$ Ribonuclease $\mathrm{H}$ was added to each tube to eliminate any RNA-cDNA strands. The same protocol was performed with positive and negative controls (reagent mixture without RNA). The cDNA was then stored at $-70^{\circ} \mathrm{C}$ before amplification. Five microliters of 1:20 cDNA of each sample (after normalization to $\beta$-actin gene) were am- plified for IFN- $\gamma$, IL-4, IL-10, TGF- $\beta$, TNF- $\alpha$, and IL-12 in a $20 \mu \mathrm{L}$ mixture containing $200 \mu \mathrm{M}$ dNTPs, $0.2 \mathrm{uM}$ of $3^{\prime}$ and $5^{\prime}$ external primers, $2.25 \mathrm{mM} \mathrm{MgCl}_{2}, 1 \times$ Gene Amp PCR buffer, and 1.25 units of AmpliTaq DNA polymerase (Perkin-Elmer/ Cetus, Norwalk, CT). A cDNA sample from a peripheral mononuclear cell of a normal individual stimulated by phorbol myristate acetate (PMA) was included as a positive control for cytokine expression for each PCR reaction. Furthermore, a reagent mixture without cDNA was used as negative control. Cycling parameters for $\beta$-actin, IFN- $\gamma$, IL-4, IL-10, IL-12, TGF- $\beta$, and TNF- $\alpha$ were 30 cycles at the following temperatures: $94^{\circ} \mathrm{C}$ for 1 minute, $60^{\circ} \mathrm{C}$ for 1 minute, $72^{\circ} \mathrm{C}$ for 1 minute, and 30 seconds in a thermal cycler reactor (PerkinElmer /Cetus, Norwalk, CT).

The statistical package Epi-Info 6.0 (USD, Inc., Stone Mountain, GA) was used for data analysis. Categorical data were compared using the $\chi^{2}$ test with Yates' correction or Fisher's exact test, and continuous data were compared using the Mann-Whitney $U$ test or Kruskall-Wallis test. Linear regression analysis was used to compare the duration of ulcer and immunologic or cytologic parameters. A $P$ value of $<0.05$ was considered statistically significant.

\section{RESULTS}

In 22 patients lymphadenopathy was observed prior to skin lesion development (early phase) whereas in 29 the lymphadenopathy occurred after reporting the appearance of skin lesions (late phase). L. braziliensis was isolated in all aspirate samples collected. The number of enlarged LNs varied from one to three (mean $1.4 \pm 0.6$ [SD]), with a mean size of $4.2 \pm$ $1.9 \mathrm{~cm}$ (range: $1-10 \mathrm{~cm}$ ). Contrary to prior work carried out by our group, ${ }^{2}$ all early-phase patients in this series displayed skin ulcers at various times post diagnosis. The duration of ulcer lesions was $36.2 \pm 29.8$ days for all patients. The skin lesions of 16 patients lasted less than 30 days, 24 patients between 30 and 60 days, and 11 patients more than 60 days. The lesion distribution was predominantly below the diaphragm $(83.3 \%)$. The history of regional LN enlargement prior to the appearance of skin ulcers in the early phase groups was variable (mean $15.3 \pm 5.1$ days; range: $7-20$ days). There were no differences between the groups regarding clinical response to specific therapy (Table 1). The demo-

TABLE 1

Demographic and clinical features of the patients studied

\begin{tabular}{|c|c|c|c|}
\hline Feature & Early phase & Late phase & Total \\
\hline Number of patients & 22 & 29 & 51 \\
\hline Age mean (range) & $22.5(9-43)$ & $26.5(12-62)$ & $24.5(9-62)$ \\
\hline Male & $15(68.2 \%)$ & $23(79.3 \%)$ & $38(74.5 \%)$ \\
\hline Lymph node size $(\mathrm{cm})$ mean \pm SD & $4.0 \pm 1.5$ & $4.4 \pm 2.0$ & $4.2 \pm 1.9$ \\
\hline \multicolumn{4}{|l|}{ Referred duration of lymphadenopathy before } \\
\hline lesion development in days $($ mean $\pm \mathrm{SD})$ & $15.3 \pm 5.1$ & NR & NA \\
\hline Duration of skin lesion in days (mean $\pm \mathrm{SD}$ ) & $35.4 \pm 25.3$ & $39.2 \pm 25.5$ & $36.2 \pm 29.8$ \\
\hline \multicolumn{4}{|l|}{ Location of the skin lesion $(\%)$} \\
\hline Above the diaphragm & $2(9.0 \%)$ & $4(14.0 \%)$ & $6(12.5 \%)$ \\
\hline Below the diaphragm & $18(82 \%)$ & $24(82.5 \%)$ & $39(83.3 \%)$ \\
\hline Both sides of the diaphragm & $2(9.0 \%)$ & $1(3.5 \%)$ & $3(4.2 \%)$ \\
\hline \multicolumn{4}{|l|}{ Therapy response } \\
\hline Cured & 19 & 25 & 44 \\
\hline Uncured/relapse & 3 & 4 & 7 \\
\hline
\end{tabular}

SD, standard deviation; NR, not referred; NA, not applicable. 
TABLE 2

Differential cell morphology in lymph node aspirates of cutaneous leishmaniasis patients

\begin{tabular}{|c|c|c|c|c|c|}
\hline Group & Lymphocytes* & Plasma cells* & Monocytes* & Neutrophils* & Eosinphils* \\
\hline Lymphadenopathy without skin lesion $(\mathrm{n}=11)$ & $87.9 \pm 11.3$ & $0.8 \pm 0.8 \dagger$ & $4.6 \pm 4.3$ & $4.3 \pm 7.7 \dagger$ & $2.2 \pm 4.5 \dagger$ \\
\hline Lymphadenopathy with skin lesion $(\mathrm{n}=9)$ & $90.4 \pm 0.8$ & $1.8 \pm 3.9 \dagger$ & $5.7 \pm 5.3$ & $1.4 \pm 1.9 \dagger$ & 0 \\
\hline
\end{tabular}

$*$ Percent distribution; mean $\pm \mathrm{SD}$.

$\dagger \mathrm{p}<0.05$ between the two groups (mann-Whitney U test).

Cell suspension from lymph node aspirates of each volunteer was centrifuged and stained with Diff-Quick stain set for microscopic examination by two observers. Differential counting was performed for each 100 cells by optical microscopy $(\times 1000)$.

graphic and clinical features of the patients studied are summarized in Table 1.

To better characterize the observed patterns of lymphadenopathy, LN cellular analysis was performed in 11 patients in the early phase and in 9 patients in the late phase of CL, sorted randomly in each group (Table 2). Patients in the early phase exhibited a higher proportion of neutrophils and eosinophils when compared with patients in late phase $(4.3 \pm 7.7$ versus $1.4 \pm 1.9$ and $2.2 \pm 45$ versus none, respectively, $P<$ $0.05)$. Patients in the late phase presented a higher proportion of plasma cells compared with patients in the early phase $(1.8 \pm 3.9$ versus $0.8 \pm 0.8, P<0.05)$. Lymphocytes predominated in both groups with no statistically significant difference between groups. The two groups also failed to differ in the proportion of monocytes (Table 2). A number of qualitative morphologic alterations were observed in the cytologic analysis of LN aspirates, such as giant cells $(7 / 20 ; 35 \%)$, foam cells $(2 / 20 ; 10 \%)$, and granuloma-like formation $(1 / 20 ; 5 \%)$, without any distinction between the two groups. Early-phase patients exhibited a higher proportion of CD8+ T cells compared with patients in the late phase $(18.5 \pm 10.7$ versus $10.9 \pm 3.6$ respectively, $P<0.05$, Table 3 ). B lymphocytes (CD19+), on the other hand, predominated in patients in the late phase in relation to patients in the early phase $(47.9 \pm$ 11.2 versus $29.3 \pm 17.4$ respectively, $P<0.05)$. No differences were observed in CD56, CD1a, CD3, or CD4 expression among the groups studied.

To assess whether diverse LN cellular constitution displayed by different clinical manifestations of CL correlates with cytokine patterns, cytokine gene expression by RT-PCR was performed in LN cells of 10 early-phase patients and 9 late-phase patients. For these experiments, patients were randomly sorted. No IL-10 expression was observed in any of the 10 patients in the early phase, however, a remarkable IL-10 gene expression was observed in 8 of the 10 late-phase patients (one had a moderate signal and the other a low signal) (Figure 1A). Expression of IL-4 was high in most late-phase patients with a wide variation in early-phase patients; these differences had little statistical significance (Figure 1B). A signal for IFN- $\gamma$ varied among all patients and did not differ between the two groups (Figure $1 \mathrm{C}$ ). TNF- $\alpha$ was highly ex- pressed in all patients studied and IL-12 and TGF- $\beta$ did not differ between groups studied either (data not shown).

\section{DISCUSSION}

A significantly higher proportion of neutrophils and eosinophils was observed in LN aspirates from patients with lymphadenopathy without skin ulcers compared with patients in whom skin lesions had already developed. These data reinforce our clinical observations and favor our stratification in early-phase and late-phase lymphadenopathy. The factors involved in early neutrophil recruitment are not elucidated in the enlarged LN in CL. Neutrophil recruitment in response to Leishmania antigen-stimulation differs between susceptible and resistant mice. ${ }^{16}$ Neutrophils are rapidly recruited to the site of murine infection where they are able to combat parasites by oxidative burst and inflammatory mediator release. ${ }^{17}$ However, in vitro ingestion by human macrophages of L. major inside apoptotic neutrophils leads to an increased release of TGF- $\beta^{18}$ making phagocytes permissive for replication. Furthermore, in vivo, neutrophils seem to contribute to the early control of L. infantum infection in the spleen but not in the liver, although no significant effect was evident at later stages of infection in either of these target organs. ${ }^{19}$ Neutrophils, rather than dendritic cells, have been implicated in carrying BCG from the skin into the draining LN. ${ }^{20}$ In lymphoid organs, neutrophils might be involved in the cross-priming of CD8+ T cells by dendritic cells that have ingested the pathogen inside neutrophils, as shown for Listeria monocytogenes. $^{21}$ In leishmaniasis, something similar may occur and the accumulation of neutrophils in the draining LN may optimize $\mathrm{T}$ cell priming earlier in the infection, favoring the anti-Leishmania acquired immune response.

CD8+ cells were more frequent in LNs of patients who presented lymphadenopathy before the development of skin lesions. In murine models of leishmaniasis, CD8+ cells seem to participate in a protective immune response. ${ }^{22-25}$ Nevertheless, C57BL/6 mice with $\beta 2$-microglobulin or CD8 deficiencies maintain their ability to heal, suggesting that CD8+ $\mathrm{T}$ cells are not required for control of primary infection. ${ }^{26-28}$

TABLE 3

Immuno-phenotyping of lymph node cells from cutaneous leishmaniasis patients

\begin{tabular}{|c|c|c|c|c|c|c|}
\hline Group & $\mathrm{CD} 3+*$ & CD4+* & CD8+* & CD19+* & CD56+* & $\overline{C D} 1 \alpha+*$ \\
\hline Lymphadenopathy without skin lesion $(\mathrm{n}=7)$ & $49.7 \pm 4.2$ & $34.7 \pm 9.9$ & $18.5 \pm 10.7 \dagger$ & $29.3 \pm 17.4 \dagger$ & $3.4 \pm 4.4$ & $1.6 \pm 1.7$ \\
\hline Lymphadenopathy with skin lesion $(\mathrm{n}=12)$ & $44.6 \pm 11$ & $27.1 \pm 9.5$ & $10.9 \pm 3.6 \dagger$ & $47.9 \pm 11.2 \dagger$ & $1.2 \pm 1.5$ & $0.3 \pm 0.1$ \\
\hline
\end{tabular}

$*$ Percent distribution; mean \pm SD.

$\dagger \mathrm{p}<0.05$ between the two groups (Mann-Whitney U test)

Lymph node aspirates were fixed and stained for cytometric analyzes as described in methods. CD3 is a surface marker of general T cells; CD4 or CD8 identify of T helper or T cytotoxic lymphocytes, respectively; CD19 is a major marker of mature B cells; CD56 marks NK cells; and CD1a identifies dendritic cells. 

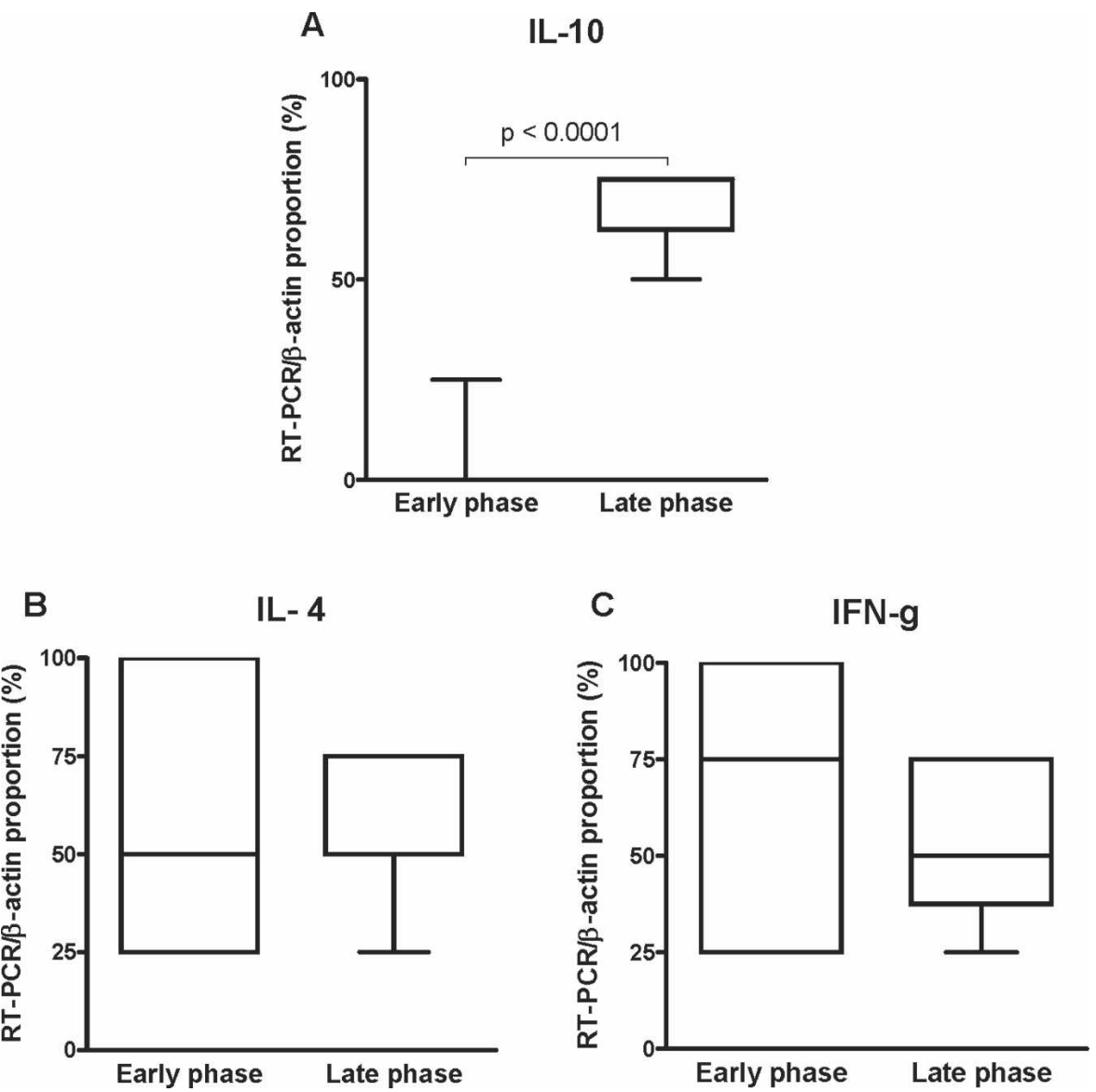

FIGURE 1. Cytokine mRNA expression by lymph node cell population in patients with cutaneous leishmaniasis lymphadenopathy with or without skin ulcer. Total mRNA was isolated from lymph node cells without in vitro antigen stimulation as described in Methods section. Bars represent box and whiskers of the proportion between the expression of (A) IL-10, (B) IL-4, and (C) IFN- $\gamma$, and the housekeeping gene $\beta$-actin. Mann-Whitney test was used to compare values.

Increased numbers of reactive CD8+ cells were observed after clinical recovering from human $\mathrm{CL}^{29}$ as well as after vaccination. ${ }^{16}$ On the other hand, cytotoxic responses were higher in mucosal leishmaniasis than in CL patients ${ }^{30}$ and activated CD8+ cells are present within lesions of CL patients $^{31}$ suggesting that CD $8+$ cells may contribute to the development of ulceration. Our present results indicate that an expanded CD8+ cell population in the draining LN precedes ulcer development. Therefore, cytotoxicity and IFN- $\gamma$ production mediated by CD8+ cells may be important for the early containment of Leishmania infection.

A remarkable finding was the higher presence of CD19+ cells in CL late-phase patients LN than in early-phase patients. The role of B cells in leishmaniasis is not clear. High antibody levels are present in the anergic diffuse cutaneous leishmaniasis (DCL), ${ }^{32,33}$ but B-cell infiltration is higher in CL than in DCL lesions. ${ }^{34} \mathrm{~B}$-cell depletion does not alter the susceptibility or resistance pattern to Leishmania infection in mice. ${ }^{35,36}$ Additionally $\mathrm{B}$ cells seem to be important to induce anti-Leishmania $\mathrm{CD} 4^{+}$Th1 cells and a DTH reaction. ${ }^{37}$

Mixed Th1-Th2 patterns, as reported here, were observed at the initial stages of experimental Leishmania infection ${ }^{38}$ and with intra-lesional cells from CL patients. ${ }^{39}$ Expression of IL-10 was higher in patients with lymphadenopathy and ulcers than in patients with lymphadenopathy alone. This cytokine seems to mediate immune suppression in chronic $\mathrm{CL}^{40}$ and in mucosal leishmaniasis. ${ }^{41}$ At early phases of CL, an elevated expression of IL-10 in LN together with IL-4 may modulate initial immune response and favor the persistence of the parasite.

Aspiration of enlarged LNs in CL is an easy and safe procedure that may help in confirming a parasitological diagnosis. Leishmania is frequently identified even under direct microscopic observation $^{2}$ as well as by elucidating early aspects of human anti-Leishmania immune response, as shown in the present report.

Received April 11, 2007. Accepted for publication July 24, 2007.

Acknowledgments: The authors thank João Santana da Silva (Faculdade de Medicina de Ribeirão Preto-USP) for the primers sequences information, Ednaldo Lima Lago and his team for fieldwork support and Edgar Carvalho and Claudia Brodskyn for valuable suggestions.

Financial support: This study was supported by Conselho Nacional de Desenvolvimento Científico e Tecnológico- Brazil (CNPq), Fundação de Amparo à Pesquisa do Estado da Bahia-Brazil (FAPESB), and FIOCRUZ. M. Barral-Netto and A. Barral are senior investigators from CNPq.

There are no commercial or other associations that might pose a conflict of interest.

Authors' addresses: Glória Bomfim and Silvane Santos, Serviço de Imunologia, Hospital Universitário Professor Edgard Santos, Rua João das Botas, s/n, Salvador, Bahia, Brazil. Bruno B. Andrade, Jorge 
Clarêncio, Manoel Barral-Netto, and Aldina Barral, Centro de Pesquisas Gonçalo Moniz, FIOCRUZ, Rua Waldemar Falcão, 121, Candeal. Salvador, Bahia, Brazil.

Reprint requests: Aldina Barral, Laboratório de Imunoparasitologia, Centro de Pesquisas Gonçalo Moniz, FIOCRUZ, Rua Waldemar Falcão, 121, Candeal. CEP: 40295-001 Salvador, Bahia, Brazil. Phone: 5571 3176-2259. Fax: 5571 3176-2279. E-mail: abarral@bahia .fiocruz.br.

\section{REFERENCES}

1. Barral A, Barral-Netto M, Almeida R, de Jesus AR, Grimaldi Junior G, Netto EM, Santos I, Bacellar O, Carvalho EM, 1992. Lymphadenopathy associated with Leishmania braziliensis cutaneous infection. Am J Trop Med Hyg 47: 587-592.

2. Barral A, Guerreiro J, Bomfim G, Correia D, Barral-Netto M, Carvalho EM, 1995. Lymphadenopathy as the first sign of human cutaneous infection by Leishmania braziliensis. Am J Trop Med Hyg 53: 256-259.

3. Sousa Ade Q, Parise ME, Pompeu MM, Coehlo Filho JM, Vasconcelos IA, Lima JW, Oliveira EG, Vasconcelos AW, David JR, Maguire JH, 1995. Bubonic leishmaniasis: a common manifestation of Leishmania (Viannia) braziliensis infection in Ceara, Brazil. Am J Trop Med Hyg 53: 380-385.

4. Azadeh B, 1985. "Localized" Leishmania lymphadenitis: a light and electron microscopic study. Am J Trop Med Hyg 34: 447455.

5. Berger TG, Meltzer MS, Oster CN, 1985. Lymph node involvement in leishmaniasis. J Am Acad Dermatol 12: 993-996.

6. al-Gindan Y, Kubba R, el-Hassan AM, Omer AH, Kutty MK, Saeed MB, 1989. Dissemination in cutaneous leishmaniasis. 3. Lymph node involvement. Int J Dermatol 28: 248-254.

7. Moraes MA, Correia Filho D, Santos JB, 1993. Lymphadenopathies in American cutaneous leishmaniasis: comments on 2 cases. Rev Soc Bras Med Trop 26: 181-185.

8. Reed SG, Badaro R, Masur H, Carvalho EM, Lorenco R, Lisboa A, Teixeira R, Johnson WD Jr, Jones TC, 1986. Selection of a skin test antigen for American visceral leishmaniasis. Am J Trop Med Hyg 35: 79-85.

9. Moll H, Fuchs H, Blank C, Rollinghoff M, 1993. Langerhans cells transport Leishmania major from the infected skin to the draining lymph node for presentation to antigen-specific $\mathrm{T}$ cells. Eur J Immunol 23: 1595-1601.

10. Sacks D, Noben-Trauth N, 2002. The immunology of susceptibility and resistance to Leishmania major in mice. Nat Rev Immunol 2: 845-858.

11. Nathan CF, Murray HW, Wiebe ME, Rubin BY, 1983. Identification of interferon-gamma as the lymphokine that activates human macrophage oxidative metabolism and antimicrobial activity. J Exp Med 158: 670-689.

12. Grimaldi G Jr, David JR, McMahon-Pratt D, 1987. Identification and distribution of New World Leishmania species characterized by serodeme analysis using monoclonal antibodies. Am J Trop Med Hyg 36: 270-287.

13. Jaffe CL, Bennett E, Grimaldi G Jr, McMahon-Pratt D, 1984. Production and characterization of species-specific monoclonal antibodies against Leishmania donovani for immunodiagnosis. J Immunol 133: 440-447.

14. McMahon-Pratt D, Bennett E, David JR, 1982. Monoclonal antibodies that distinguish subspecies of Leishmania braziliensis. J Immunol 129: 926-927.

15. Bomfim G, Nascimento C, Costa J, Carvalho EM, Barral-Netto M, Barral A, 1996. Variation of cytokine patterns related to therapeutic response in diffuse cutaneous leishmaniasis. Exp Parasitol 84: 188-194.

16. Pompeu MM, Brodskyn C, Teixeira MJ, Clarencio J, Van Weyenberg J, Coelho IC, Cardoso SA, Barral A, Barral-Netto M, 2001. Differences in gamma interferon production in vitro predict the pace of the in vivo response to Leishmania amazonensis in healthy volunteers. Infect Immun 69: 7453-7460.

17. Nathan C, 2006. Neutrophils and immunity: challenges and opportunities. Nat Rev Immunol 6: 173-182.

18. van Zandbergen G, Klinger M, Mueller A, Dannenberg S, Gebert A, Solbach W, Laskay T, 2004. Cutting edge: neutrophil granulocyte serves as a vector for Leishmania entry into macrophages. J Immunol 173: 6521-6525.

19. Rousseau D, Demartino S, Ferrua B, Michiels JF, Anjuere F, Fragaki K, Le Fichoux Y, Kubar J, 2001. In vivo involvement of polymorphonuclear neutrophils in Leishmania infantum infection. BMC Microbiol 1: 17.

20. Abadie V, Badell E, Douillard P, Ensergueix D, Leenen PJ, Tanguy M, Fiette L, Saeland S, Gicquel B, Winter N, 2005. Neutrophils rapidly migrate via lymphatics after Mycobacterium bovis BCG intradermal vaccination and shuttle live bacilli to the draining lymph nodes. Blood 106: 1843-1850.

21. Tvinnereim AR, Hamilton SE, Harty JT, 2004. Neutrophil involvement in cross-priming $\mathrm{CD} 8+\mathrm{T}$ cell responses to bacterial antigens. J Immunol 173: 1994-2002.

22. Hill JO, Awwad M, North RJ, 1989. Elimination of CD4+ suppressor $\mathrm{T}$ cells from susceptible BALB/c mice releases CD8+ T lymphocytes to mediate protective immunity against Leishmania. J Exp Med 169: 1819-1827.

23. Milon G, Titus RG, Cerottini JC, Marchal G, Louis JA, 1986. Higher frequency of Leishmania major-specific L3T4+ T cells in susceptible BALB/c as compared with resistant CBA mice. J Immunol 136: 1467-1471.

24. Smith LE, Rodrigues M, Russell DG, 1991. The interaction between CD8+ cytotoxic T cells and Leishmania-infected macrophages. $J$ Exp Med 174: 499-505.

25. Muller I, Kropf P, Louis JA, Milon G, 1994. Expansion of gamma interferon-producing $\mathrm{CD} 8+\mathrm{T}$ cells following secondary infection of mice immune to Leishmania major. Infect Immun 62: $2575-2581$.

26. Huber M, Timms E, Mak TW, Rollinghoff M, Lohoff M, 1998. Effective and long-lasting immunity against the parasite Leishmania major in CD8-deficient mice. Infect Immun 66: 39683970.

27. Overath P, Harbecke D, 1993. Course of Leishmania infection in beta 2-microglobulin-deficient mice. Immunol Lett 37: 13-17.

28. Wang ZE, Reiner SL, Hatam F, Heinzel FP, Bouvier J, Turck CW, Locksley RM, 1993. Targeted activation of CD8 cells and infection of beta 2-microglobulin-deficient mice fail to confirm a primary protective role for CD8 cells in experimental leishmaniasis. J Immunol 151: 2077-2086.

29. Da-Cruz AM, Conceicao-Silva F, Bertho AL, Coutinho SG, 1994. Leishmania-reactive CD4+ and CD8+ T cells associated with cure of human cutaneous leishmaniasis. Infect Immun 62: 2614-2618.

30. Brodskyn CI, Barral A, Boaventura V, Carvalho E, Barral-Netto M, 1997. Parasite-driven in vitro human lymphocyte cytotoxicity against autologous infected macrophages from mucosal leishmaniasis. J Immunol 159: 4467-4473.

31. Machado P, Kanitakis J, Almeida R, Chalon A, Araujo C, Carvalho EM, 2002. Evidence of in situ cytotoxicity in American cutaneous leishmaniasis. Eur J Dermatol 12: 449-451.

32. Mengistu G, Akuffo HO, Yemane-Berhan T, Britton S, Fehniger TE, 1990. Serum antibody specificities to Leishmania aethiopica antigens in patients with localized and diffuse cutaneous leishmaniasis. Parasite Immunol 12: 495-507.

33. Schurr E, Kidane K, Yemaneberhan T, Wunderlich F, 1986. Cutaneous leishmaniasis in Ethiopia: I. Lymphocyte transformation and antibody titre. Trop Med Parasitol 37: 403-408.

34. Vieira MG, Oliveira F, Arruda S, Bittencourt AL, Barbosa AA Jr, Barral-Netto M, Barral A, 2002. B-cell infiltration and frequency of cytokine producing cells differ between localized and disseminated human cutaneous leishmaniases. Mem Inst Oswaldo Cruz 97: 979-983.

35. Babai B, Louzir H, Cazenave PA, Dellagi K, 1999. Depletion of peritoneal CD5+ B cells has no effect on the course of Leishmania major infection in susceptible and resistant mice. Clin Exp Immunol 117: 123-129.

36. Brown DR, Reiner SL, 1999. Polarized helper-T-cell responses against Leishmania major in the absence of B cells. Infect Immun 67: 266-270.

37. Scott P, Natovitz $P$, Sher A, 1986. B lymphocytes are required for the generation of $\mathrm{T}$ cells that mediate healing of cutaneous leishmaniasis. J Immunol 137: 1017-1021.

38. Sommer F, Meixner M, Mannherz M, Ogilvie AL, Rollinghoff M, 
Lohoff M, 1998. Analysis of cytokine patterns produced by individual CD4+ lymph node cells during experimental murine leishmaniasis in resistant and susceptible mice. Int Immunol 10: $1853-1861$.

39. Melby PC, Andrade-Narvaez FJ, Darnell BJ, Valencia-Pacheco G, Tryon VV, Palomo-Cetina A, 1994. Increased expression of proinflammatory cytokines in chronic lesions of human cutaneous leishmaniasis. Infect Immun 62: 837-842.

40. Anderson CF, Oukka M, Kuchroo VJ, Sacks D, 2007.
CD4(+)CD25(-)Foxp3(-) Th1 cells are the source of IL-10mediated immune suppression in chronic cutaneous leishmaniasis. $J$ Exp Med 204: 285-297.

41. Faria DR, Gollob KJ, Barbosa J Jr, Schriefer A, Machado PR, Lessa H, Carvalho LP, Romano-Silva MA, de Jesus AR, Carvalho EM, Dutra WO, 2005. Decreased in situ expression of interleukin-10 receptor is correlated with the exacerbated inflammatory and cytotoxic responses observed in mucosal leishmaniasis. Infect Immun 73: 7853-7859. 